\title{
Involvement of Salicylic Acid in the Establishment of the Rhizobium meliloti-Alfalfa Symbiosis
}

\author{
F. Martínez-Abarca, ${ }^{1}$ J. A. Herrera-Cervera, ${ }^{1}$ P. Bueno, ${ }^{2}$ J. Sanjuan, ${ }^{1}$ T. Bisseling, ${ }^{3}$ and J. Olivares ${ }^{1}$ \\ ${ }^{1}$ Departamento de Microbiología del Suelo y Sistemas Simbióticos; ${ }^{2}$ Departamento de Bioquímica \\ y Biología Molecular y Celular de Plantas, Estación Experimental del Zaidín, CSIC, Profesor Albareda, \\ 1. 18008 Granada, Spain; ${ }^{3}$ Department of Molecular Biology, Wageningen Agricultural University, \\ 67034A Wageningen, The Netherlands \\ Accepted 15 October 1997.
}

\begin{abstract}
Inoculation of alfalfa plants with either incompatible $R h i$ zobium or a Rhizobium mutant blocked in Nod factor synthesis led to an accumulation of salicylic acid in roots, in contrast to plants inoculated with a wild-type (compatible) $\boldsymbol{R}$. meliloti strain. When salicylic acid was exogenously applied prior to inoculation of alfalfa plants with either purified Nod factor or compatible Rhizobium strains, a significant inhibition of nodule primordia formation and a reduction of the number of emerging nodules, respectively, as well as a delay in nodule visualization, were observed. These results suggest an involvement of Rhizobiumsynthesized Nod factors in the inhibition of salicylic acidmediated defense in legumes.
\end{abstract}

Additional keywords: hypersensitive response, plant defense, systemic acquired resistance.

Salicylic acid (SA) is an important endogenous molecule involved in plant defense. The link between SA production and systemic acquired resistance (SAR) has been well established (Klessig and Malamy 1994; Delaney 1997). Transgenic plants expressing the salicylate dehydrogenase $(n a h G)$ gene, which converts SA into inactive catechol, do not establish SAR (Gaffney et al. 1993). Furthermore, there is a correlation between an increase in SA levels and plant gene expression. Pathogenesis-related (PR) proteins show up a few hours after the SA level begins to rise (Yalpani et al. 1993). Exogenous SA can induce simultaneous PR expression and resistance to pathogens, even in the absence of pathogenic organisms (Ward et al. 1991).

Rhizobium, Bradyrhizobium, and Azorhizobium are bacteria that form nitrogen-fixing nodules on legume roots. Their association with legumes is a rather special plant-microbe interaction, in which the successful interaction does not induce a plant defense response. Several bacterial genes are essential for a successful interaction with the host. These are, for example, the nodulation (nod) genes, and the genes involved in exopolysaccharide (exo) and lipopolysaccharide

Corresponding author: J. Olivares; Estación Experimental del Zaidín, Profesor Albareda, 1. 18008 Granada, Spain; Telephone: +34 58 121011; Fax: +34 58 129600; E-mail: olivares@eez.csic.es (lps) synthesis (see Spaink 1995). Upon activation by plant flavonoids, the nod genes are transcribed and their protein products participate in the biosynthesis of Nod factors (lipochito-oligosaccharides, LCOs) (see Long 1996). These Nod factors induce at least the first steps of nodule formation. Although the function of exo and lps genes in nodulation is not completely clear, several studies strongly suggest a role in the control of the host defense response (Battisti et al. 1992; Niehaus et al. 1993; Perotto et al. 1994). In addition to lipopolysaccharide (LPS) and exopolysaccharide (EPS), Nod factors might also play a role in controlling defense, as suggested by the fact that Nod factors can act as elicitors of phytoalexins biosynthesis (Savouré et al. 1994, 1997). Furthermore, Vasse et al. (1993) showed that, in a compatible interaction, the bacteria induce a hypersensitive response (HR), and propose that this is part of the plant mechanism controlling the number of successful infections. During the recognition process, either the plant discriminates between the mutualistic and the pathogenic bacteria, or the mutualistic ones elude the host defense response. McKhann et al. (1997), studying the expression of genes of the PAL pathway, suggest that, somehow, rhizobia prevent the triggering of the host defense response. Several reports referring to the resemblance between Rhizobium-legume infection and pathogenic organism-plant interactions have been published (Baron and Zambriski 1995; Djordjevic et al. 1986; Long and Staskawicz 1993; Vance 1983).

To determine whether Nod factors might be involved in controlling host defense responses, we quantified SA accumulation in alfalfa plants inoculated with compatible $(R$. meliloti wild type) or incompatible ( $R$. leguminosarum bv. trifolii) rhizobia as well as a nod mutant of $R$. meliloti defective in LCO synthesis.

Ten-day-old alfalfa plants (cv. Aragón), axenically grown in test tubes as previously described (Olivares et al. 1980), were inoculated with $10^{8}$ cell $\cdot \mathrm{ml}^{-1}$ of $R$. meliloti strain AK631 or the nod mutant AK1672 ( NodC $^{-}$) (Kondorosi et al. 1984) taken from a 24 -h culture grown in tryptone-yeast extract medium. Cells were washed twice to remove the culture medium. Fifty to 100 plant roots were harvested and frozen in liquid nitrogen 4, 8, 12, 24, and $48 \mathrm{~h}$ after inoculation, and SA content was analyzed according to Rasmussen et al. (1991). 
Figure 1 presents data from a representative experiment. It clearly shows a different pattern of SA accumulation in roots inoculated with $R$. meliloti wild type or the $\mathrm{NodC}^{-}$mutant. SA content in roots inoculated with the wild-type strain remained close to basal levels, whereas in those inoculated with the

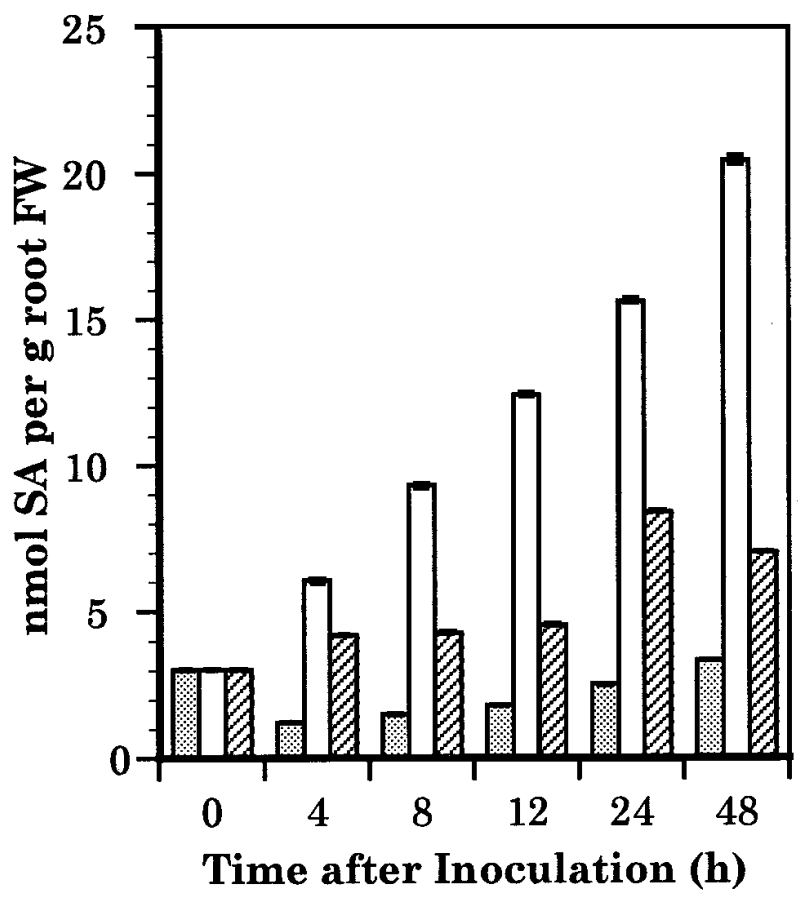

Fig. 1. Salicylic acid (SA) accumulation, expressed as nmol per $g$ of root fresh weight $(\mathrm{FW})$, in roots of alfalfa plants, noninoculated $(0 \mathrm{~h})$, or inoculated with Rhizobium meliloti wild type (dotted bars), $\mathrm{NodC}^{-}$mutant (white bars), and R. leguminosarum bv. trifolii (hatched bars) at different times after inoculation. Each data point reported is the average of the amount of SA detected in three replicate samples from one representative experiment. Each experiment was performed at least three times. The value of each replicate is the mean of 5 fluorescent readings taken over $10 \mathrm{~s}$. The detection limit of SA was $1 \mathrm{nmol} \mathrm{ml}^{-1}$.

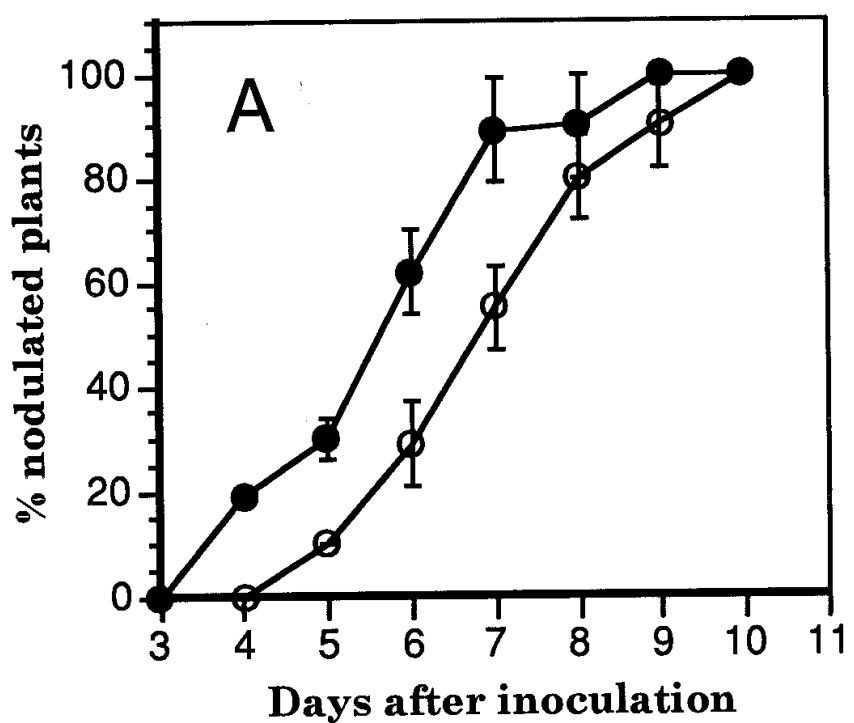

NodC $^{-}$mutant it increased markedly and was already apparent $4 \mathrm{~h}$ after inoculation. Inoculation of alfalfa with $R$. leguminosarum bv. trifolii, strain Rt103 (this laboratory), also induces SA accumulation, compared with $R$. meliloti wild type. Thus, the production of specific Nod factors seems to suppress the accumulation of SA induced by the bacteria.

The effect of exogenously applied SA was analyzed on two parameters of the $R$. meliloti-alfalfa association: nodulation kinetics and the number of nodules formed. Ten-day-old plants, prepared as above, were inoculated with $R$. meliloti AK631 to a final concentration of $10^{6} \mathrm{cell} \cdot \mathrm{ml}^{-1}$. SA $(25 \mu \mathrm{M})$ in the form of sodium salt (Sigma, St. Louis, MO) was added to plant growth medium $24 \mathrm{~h}$ prior to bacterial inoculation. Previously, we found that $25 \mu \mathrm{M}$ SA added to the nutrient solution did not affect shoot and root plant development and

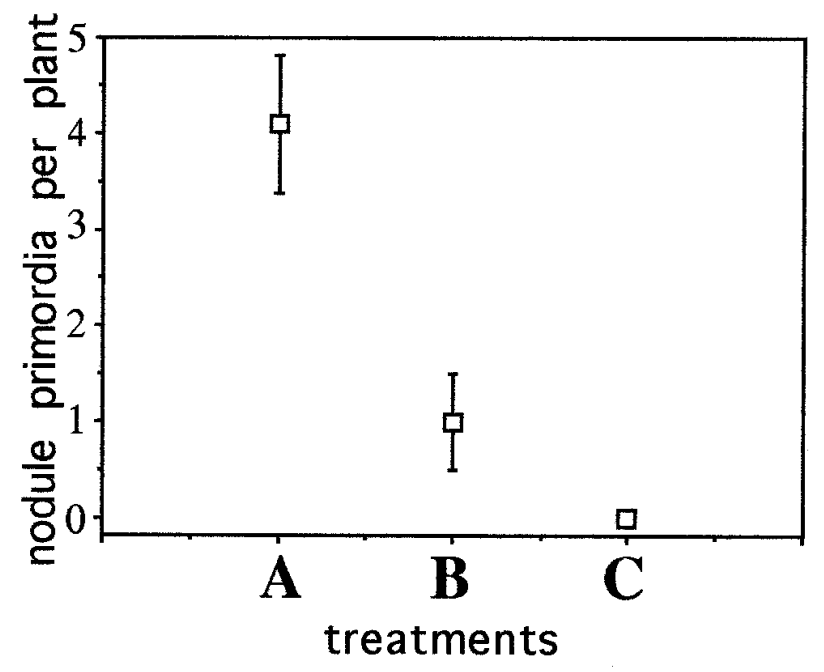

Fig. 3. Effect of exogenous application of salicylic acid (SA) on Nod factor-induced nodule primordia on alfalfa plants. A, $10^{-7} \mathrm{M}$ NodRm-1. B, $10^{-7}$ M NodRm-1 plus $25 \mu \mathrm{M}$ SA. C, $25 \mu \mathrm{M} \mathrm{SA}$. Standard errors are represented by bars.

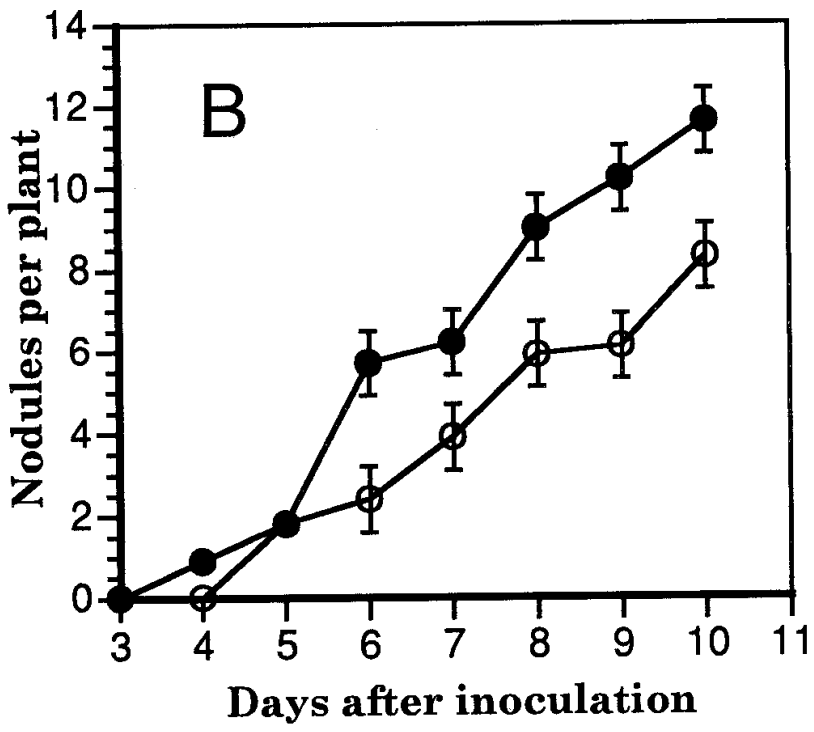

Fig. 2. Effect of the addition of $25 \mu \mathrm{M}$ sodium salicylate to the plant growth mineral solution $24 \mathrm{~h}$ before the inoculation of alfalfa plants with Rhizobium meliloti GR4. A, Percentage of nodulated plants. B, Number of nodules per plant. Open circles correpond to the treatment with salicylic acid and filled circles to the control. Standard errors are represented by bars on each data point. 
chlorophyll concentration. SA application caused a marked delay in nodule emergence (Fig. 2A) as well as a significant decrease in the number of nodules (Fig. 2B).

To understand which step of the nodulation process could be affected by the increased SA levels, we studied the effect of exogenous SA application on nodule primordia formation induced by Nod factors of $R$. meliloti. The nutrient solution of 5-day-old plants was supplemented with $10^{-7} \mathrm{M}$ NodRm-1 (obtained according to Lerouge et al. 1990), alone or together with $25 \mu \mathrm{M}$ SA. Eight days later, roots were collected and cleared with sodium hypochlorite (Truchet et al. 1989). The number of putative nodules was determined by visually scoring root deformations clearly differentiated from secondary roots. Results obtained (Fig. 3) showed that the addition of 25 $\mathrm{mM}$ SA significantly decreased the number of nodule primordia induced by Nod factors (down to $25 \%$ of the control). These results demonstrate that SA could interfere in a specific way with nodule organogenesis.

Twenty-five $\mu$ M SA shows a low inhibitory effect (ca. 10\%) on $R$. meliloti growth. One could think that the effect observed on the nodulation kinetics and nodule number formed when SA is added to plants could be due to this inhibitory effect. However, inocula density has no significant effect on the number of nodules formed (Olivares et al. 1980). Moreover, the inhibitory effect of exogenous SA on nodule primordia induction by Nod factor in alfalfa plants supports the conclusion that SA directly affects the nodulation process rather than bacterial fitness.

Considering the relationship between pathogenic-induced SA synthesis in plants and the expression of SAR (Klessig and Malamy 1994), it can be argued that a defense mechanism associated with SA accumulation takes place in the establishment of the Rhizobium-legume symbiosis. The suppression of the defense response only occurs when the plant recognizes its correct partner, producing a compatible Nod factor. Salzwedel and Dazzo (1993) reported an increased peroxidase activity in roots elicited by heterologous Rhizobium as a plant defense response that contributes to expression of host specificity during the infection process. Peroxidase induction could be related to the triggering of the defense response. This enzyme activity could be required for lignification and, possibly, for cell wall protein cross-linking.

Our results strongly suggest that Nod factors, in addition to their well-established role in root infection and nodulation, control the suppression of the SA accumulation. This is essential to facilitate the formation of nodule primordia. Our results also suggest that Rhizobium produces unidentified elicitors that induce SA accumulation in the host. Compatible Nod factor production would inhibit either their synthesis or their recognition by the plant.

\section{ACKNOWLEDGMENTS}

We thank A. Kondorosi for supplying strain AK631 and its derivative NodC ${ }^{-}$. This work has been supported by the Plan Andaluz de Investigación (PAI).

\section{LITERATURE CITED}

Baron, C., and Zambriski, P. C. 1995. The plant response in pathogenesis, symbiosis, and wounding: Variations in a common theme. Annu.
Rev. Genet. 29:107-129.

Battisti, L., Lara, J. C., and Leigh, J. A. 1992. Specific oligosaccharide form of the Rhizobium meliloti exopolysaccharide promotes nodule invasion in alfalfa. Proc. Natl. Acad. Sci. USA 89:5625-5629.

Delaney, T. P. 1997. Genetic dissection of acquired resistance to disease. Plant Physiol. 113:5-12.

Djordjevic, M. A., Gabriel, D. W., and Rolfe, B. G. 1986. Rhizobium. The refined parasite of legumes. Annu. Rev. Phytopathol. 46:497-531.

Gaffney, T., Friedrich, L., Vernooij, B., Negrotto, D., Nye, G., Uknes, S., Ward, E., Kessman, H., and Ryals, J. 1993. Requirement of salicylic acid for the induction of acquired resistance. Science 261:754-756.

Klessig, D. F., and Malamy, J. 1994. The salicylic acid signal in plants. Plant Mol. Biol. 26:1439-1458.

Kondorosi, E., Banfalvi, Z., and Kondorosi, A. 1984. Physical and genetic analysis of a symbiotic region of Rhizobium meliloti: Identification of nodulation genes. Mol. Gen. Genet. 193:445-456.

Lerouge, P., Roceh, P., Faucher, C., Maillet, F., Truchet, G., Promé, J. C., and Denarié, J. 1990. Symbiotic host-specificity of Rhizobium meliloti determined by a sulphated and acylated glucosamine oligosaccharide signal. Nature 344:781-784.

Long, S. R. 1996. Rhizobium symbiosis: Nod factors in perspective. Plant Cell 8:1885-1898.

Long, S. R., and Staskawicz, B. J. 1993. Prokaryotic plant parasites. Cell 73:21-935.

McKhann, H. I., Paiva, N. L., Dioxin, R. A., and Hirsute, A. M. 1997. Chalcone synthase transcripts are detected in alfalfa root hairs following inoculation with wild-type Rhizobium meliloti. Mol. PlantMicrobe Interact.10:50-58

Niehaus, K., Kappa, D., and Pühler, A. 1993. Plant defence and delayed infection of alfalfa pseudonodules and exopolysaccharide (EPS-I) deficient Rhizobium meliloti mutant. Planta 190:415-425.

Olivares, J., Casadesús, J., and Bedmar, E. J. 1980. Method for testing degree of infectivity of Rhizobium meliloti strains. Appl. Environ. Microbiol. 56:389-393.

Perotto, S., Brewin, N. J., and Kannenberg, E. L. 1994. Cytological evidence for a host defense response that reduces cell and tissue invasion in pea nodules by lipopolysaccharide-defective mutants of Rhizobium leguminosarum strain 3841. Mol. Plant-Microbe Interact. 7:99-112.

Rasmussen, J. B., Hammerschmidt, R., and Zook, M. N. 1991. Systemic induction of salicylic acid accumulation in cucumber after inoculation with Pseudomonas syringae pv. syringae. Plant Physiol. 97:13421347.

Salzwedel, J. L., and Dazzo, F. B. 1993. pSym nod gene influence on elicitation of peroxidase activity from white clover and pea roots by rhizobia and their cell-free supernatant. Mol. Plant-Microbe Interact. 6:127-134

Savouré, A., Magyar, Z., Pierre, M., Brown, S., Schultze, M., Dudits, D., Kondorosi, A., and Kondorosi, E. 1994. Activation of the cell cycle machinery and the isoflavonoid biosynthesis pathway by active Rhizobium meliloti Nod signal molecules in microcallus Medicago suspensions. EMBO J. 13:1093-1102.

Savouré, A., Sallaud, C., El-Turk, J., Zuanazzi J., Ratet, P., Schultze, M., Kondorosi, A., Esnault, R., and Kondorosi, E. 1997. Distinct response of Medicago suspension cultures and roots to Nod factors and chitin oligomers in the elicitation of defense-related responses. Plant J. 11: 277-287.

Spaink, H. P. 1995. The molecular basis of infection and nodulation by rhizobia: The ins and outs of sympathogenesis. Annu. Rev. Phytopathol. 33:345-368

Truchet, G., Camut, S., de Billy, F., Odorico, R., and Vasse, J. 1989. The Rhizobium-legume symbiosis. Two methods to discriminate between nodules and other root derived structures. Protoplasma 149:82-88.

Vance, C. P. 1983. Rhizobium infection and nodulation: A beneficial plant disease? Annu. Rev. Microbiol. 37:399-424.

Vasse, J., de Billy, F., and Truchet, G. 1993. Abortion of infection during the Rhizobium meliloti-alfalfa symbiotic interaction is accompanied by a hypersensitive reaction. Plant J. 4:555-566.

Ward, E. R., Ulknes, S. J., Williams, S. C., Dincher, S. S., Wiederhol, D. L., Alexander, D. C., Ahl-Goy, P., Métraux, J. P., and Ryals, J. 1991. Coordinate gene activity in response to agents that induce systemic acquired resistance. Plant Cell 3:1085-1094.

Yalpani, N., Shulaev, V., and Raskin, I. 1993. Endogenous salicylic acid levels correlate with accumulation of pathogenesis-related proteins and virus resistance in tobacco. Phytopathology 83:702-708. 